\title{
Juridische vraagstukken rond arbeid in de klusseneconomie
}

\author{
Mijke Houwerzijl*
}

In de derde bijdrage van het Dossier bespreken we de juridische consequenties van het werken in een klusseneconomie. We belichten een aantal juridische aspecten die kleven aan de sociaal-politieke vraag naar het maatschappelijk gewenste minimumniveau aan bescherming voor platformwerkers. Daarbij gaat de meeste aandacht uit naar de kwalificatievraag: zijn werkenden in de klusseneconomie werknemers of zelfstandigen zonder personeel (zzp'ers)? Voor de rechtsonzekerheid die hiermee gepaard gaat, is een aantal oplossingen in de maak of soms al voorhanden in het geldende recht. Deze oplossingen worden kort verkend.

\section{Inleiding}

'In the future, employees won't exist. Contract work is becoming the new normal', aldus de Amerikaanse ondernemer Ted Milbourn (techcrunch.com: Milbourn, 2015). Ook Nederland kent aanhangers van de stelling dat de toekomst van werk toebehoort aan zzp'ers. De uitspraak van Milbourn had echter specifiek betrekking op de - in Amerika begonnen - opkomst van werk en diensten die op afroep aangeboden kunnen worden via online platforms, doorgaans tegen betaling (ShareNL, 2015, 14). Een bijzondere factor in deze klusseneconomie (gig-economy) in wording vormt de mondiale schaal waarop platformwerk kan worden ingevoerd. Zo hanteert Uber een app die overal ter wereld gebruikt kan worden. De manier waarop een Uber-chauffeur in Californië, Londen en de Nederlandse Randstad opereert, komt dus in grote lijnen overeen. Mede als gevolg daarvan woeden in veel landen soortgelijke discussies over de positie van werkenden in de klusseneconomie. Ook staat het onderwerp sterk in de belangstelling van de Europese Unie. In de medio 2016 gelanceerde European Agenda for the Collaborative Economy (deeleconomie) wordt expliciet de positie van platformwerkers aan de orde gesteld (COM/2016). De Europese Commissie roept de lidstaten op te evalueren of hun nationale vereisten inzake arbeidsverhoudingen toereikend zijn en heeft eind vorig jaar zelf een mede op platformwerk toegesneden richtlijnvoorstel gedaan dat de transparantie en voorspelbaarheid van 'atypische' arbeidsrelaties zou moeten verbeteren (COM/2017).

In deze bijdrage ga ik nader in op een aantal juridische aspecten van de recent ook in Nederland losgebarsten maatschappelijke en academische discussie over het offline op afroep werken in de online aangestuurde klusseneconomie. Crowdwork

* Prof. mr. Mijke Houwerzijl is hoogleraar Arbeidsrecht aan de Universiteit van Tilburg en bijzonder hoogleraar Europees en rechtsvergelijkend arbeidsrecht aan de Rijksuniversiteit Groningen. 
(waarbij het werk zelf ook online wordt uitgevoerd) blijft buiten beschouwing (zie hierover onder andere Houwerzijl, 2017a; Prassl \& Risak, 2017).

\section{Politieke aandacht voor platformwerkers}

De Tweede Kamer organiseerde in november 2017 een rondetafelgesprek over werk in de platformeconomie, en het ministerie van Sociale Zaken en Werkgelegenheid (SZW) laat een onderzoek verrichten naar de omvang en de manier van werken in de klusseneconomie, dat dit voorjaar wordt verwacht. Hierbij komen ook arbeidsrechtelijke, fiscaalrechtelijke en sociaalrechtelijke aspecten van het werken in de klusseneconomie aan bod. De minister zal op basis van de uitkomsten van dat onderzoek bezien of maatregelen nodig zijn en, zo ja, welke (Kamerstuk 25883, 312, p. 31, 42).

Voor deze aandacht vanuit de politiek is alle reden. De markt voor online bemiddelde klussen is klein maar groeit snel, zo is de communis opinio in de media en bij beleidsmakers. Overigens verdient opmerking dat de gesignaleerde groei gebaseerd is op trendrapporten en toekomstvoorspellingen, zogenoemde weak signals. Er is nauwelijks empirisch materiaal voorhanden (Van Dijck, Poell \&De Waal, 2016, 15). Belangrijker dan de exacte omvang van het fenomeen is echter dat de groei van sommige platforms maatschappelijke problemen oplevert. Het disruptive' online taxiplatform Uber, actief in Nederland sinds 2012, fungeert als schrikbeeld van de ontregelde platformarbeidsmarkt van de toekomst. Problemen in de zeer competitieve markt voor maaltijdbezorging in de grote steden, met platforms als Deliveroo en Thuisbezorgd, vormden aanleiding voor genoemde hoorzitting in het parlement. Steeds duidelijker tekent zich het beeld af dat het ongeclausuleerd toelaten van dergelijke innovatieve platforms niet enkel leidt tot nieuwe kansen op werk, lagere prijzen en meer keuzevrijheid. Het brengt ook risico's op monopolievorming en oneerlijke concurrentie mee en lijkt nieuwe sociaaleconomische ongelijkheden te bevorderen (Frenken e.a., 2017, 98). Aldus zijn tal van publieke waarden in het geding (Kool \& Van Est, 2017). Het waarborgen van publieke waarden zonder de innovatieve kracht van de platforms (te veel) te belemmeren, stelt beleidsmakers en politici voor lastige afwegingen. Welke juridische aandachtspunten zijn van belang bij het zoeken naar een wenselijk niveau van sociale bescherming van platformwerkenden?

\section{Naar een minimumniveau van sociale bescherming?}

Een cruciaal aandachtspunt bij arbeid in de klusseneconomie is de kwalificatievraag: zijn werkenden in de klusseneconomie werknemers of zzp'ers? Voor zover bekend, heeft in Nederland een jonge fietskoerier als eerste platformwerker de kwalificatievraag aan de rechter voorgelegd. Aankondiging hiervan vond plaats op 16 november 2017, de dag van de hoorzitting van de Tweede Kamer. Bijzonder aan deze zaak tegen maaltijdbezorger Deliveroo is dat de fietskoerier als werknemer is aangenomen en zich verzet tegen het (inmiddels uitgevoerde) voornemen van het van oorsprong Britse bedrijf om vanaf 1 februari 2018 alleen nog te wer- 
ken met zzp'ers in plaats van bezorgers in loondienst. Als reactie daarop ging een deel van de Deliveroo-bezorgers in staking: om hun stem te laten horen, weigerden ze elke bestelling. Ze werden daarbij ondersteund door de door hen opgerichte 'Riders Union', onderdeel van de FNV.

Volgens de Riders Union is Deliveroo welbewust schijnzelfstandigheid aan het creëren om werkgeverspremies te vermijden en risico's af te wentelen op zijn koeriers. De koeriers krijgen als zelfstandigen een hoger inkomen (gebaseerd op het aantal ritten in plaats van op uurbasis), maar moeten zelf hun pensioen regelen, een verzekering afsluiten en draaien ook zelf op voor inkomstenderving bij ziekte (www.ridersunion.nl/nieuws, 2017). Volgens Deliveroo komt het met deze beleidswijziging juist tegemoet aan de wens van veel koeriers, die in een enquête zouden hebben aangegeven veel waarde te hechten aan flexibiliteit en het zelf indelen van roosters. Het platformbedrijf zegt bovendien dat de verouderde arbeidswetgeving niet meer past bij online platforms als Deliveroo (Deliveroohoorzitting, 2017).

Tijdens bovengenoemde hoorzitting in de Tweede Kamer uitten aanwezige platformwerkers, gesteund door de vakbonden, hun zorgen over de arbeidsomstandigheden en -voorwaarden van platformwerkers die zijn aangesteld als (schijn)zelfstandige, waaronder hun kwetsbaarheid bij arbeidsongevallen. Zij bestempelden online platforms als Deliveroo, Werkspot, Uber-eats en Helpling als werkgever en wezen erop dat de overheid moet gaan optreden tegen schijnzelfstandigheid van platformwerkers. Concurrenten van Deliveroo op de maaltijdbezorgmarkt als Foodora en Thuisbezorgd.nl zijn het hiermee eens. Zij hebben nog steeds bezorgers als werknemer in dienst en klagen erover dat het gedogen van de situatie bij Deliveroo door de Inspectie SZW en de Belastingdienst leidt tot oneerlijke concurrentie. Tegelijkertijd wijzen zij er echter op dat betaling volgens de cao de innovatie in deze branche teniet zou doen: 'Zeventig procent van onze bezorgingen vindt plaats in het weekend. Als we onze werknemers volgens de cao moeten betalen, moeten we ze op zaterdag 50 procent extra betalen. En op zondag 100 procent. Maar dan gaat onze bezorgprijs van 2,50 naar wel 10 euro. Je begrijpt dat de consument dan afhaakt' (Foodora, 2017).

\section{Voorstel in het regeerakkoord}

De discussie ligt duidelijk in het verlengde van de algemene discussie in Nederland over de toename van (schijn)zelfstandigen. De fiscale positie van een zzp'er hangt af van de vraag of deze te kwalificeren is als 'ondernemer'. Indien een zzp'er voor de inkomstenbelasting als ondernemer wordt aangemerkt, geeft dat aanspraak op allerlei fiscale faciliteiten, zoals de zelfstandigenaftrek, de startersaftrek en de MKB-winstvrijstelling. Deze faciliteiten zijn door de wetgever in het leven geroepen met als beleidsdoel het stimuleren en ondersteunen van ondernemerschap en kunnen per jaar een groot belastingvoordeel opleveren voor zzp'ers. Dit beleid was succesvol, maar levert vooral aan de onderkant van de arbeidsmarkt situaties van schijnzelfstandigheid op. 
In Vertrouwen in de toekomst (Regeerakkoord 2017-2021, 2018, 25) kondigt het kabinet een wet aan die dit moet voorkomen door een overeenkomst van opdracht die langer duurt dan drie maanden en waarbij een (te) laag tarief is afgesproken, dwingendrechtelijk te kwalificeren als een arbeidsovereenkomst. Afhankelijk van de precieze uitwerking zou dit kunnen betekenen dat de betrokkene recht krijgt op een minimumloon, ontslagbescherming, doorbetaalde vakantie, loondoorbetaling bij ziekte en tal van andere arbeidsvoorwaarden. Ook is hij dan verzekerd tegen werkloosheid en arbeidsongeschiktheid en staat vast dat hij niet zelf aansprakelijk is voor (onopzettelijke) schade.

Biedt de aangekondigde wet ook een oplossing voor te laagbetaalde platformwerkers? Los van de vraag of de regering dit beoogt, hangt het antwoord af van de contractuele (standaard)voorwaarden waaronder platformwerkers hun klussen verrichten, of zij dit in de regel incidenteel doen dan wel langer dan drie maanden én of het platform als de opdrachtgever (en dus na drie maanden als werkgever) kan worden aangemerkt.

\section{De kwalificatie van arbeid}

Hoe vindt kwalificatie van de overeenkomst plaats? Het uitgangspunt is wat partijen overeenkomen. Uber beschouwt zijn chauffeurs of 'rijders' niet als werknemers, maar als zelfstandige dienstverleners. Zo wordt in de standaardvoorwaarden die chauffeurs moeten accepteren om voor ritten in aanmerking te komen, uitdrukkelijk en bij herhaling vermeld dat er geen sprake is van een arbeidsovereenkomst. Dit model heeft bij de meeste platforms navolging gekregen. Maar voor de kwalificatie is ook de feitelijke uitvoering van de overeenkomst van belang. Uiteindelijk is wat op papier staat of op de site wordt aangevinkt dus niet doorslaggevend. Als hierover een conflict ontstaat, zal de rechter nagaan of de kwalificatie klopt met de werkelijke situatie.

De definitie van de arbeidsovereenkomst vinden we in artikel 7:610 Burgerlijk Wetboek (BW). Hierin staat dat een arbeidsovereenkomst de overeenkomst is waarbij de ene partij, de werknemer, zich verbindt in dienst van de andere partij, de werkgever, tegen loon gedurende zekere tijd arbeid te verrichten. Uit deze definitie zijn drie bestanddelen af te leiden: loon, arbeid en een gezagsverhouding (blijkend uit de zinssnede 'in dienst van de andere partij'). Van de werknemer wordt immers verwacht dat hij de instructies van de werkgever opvolgt, terwijl een zelfstandige in beginsel zelf bepaalt waar, wanneer en hoe hij zijn werk organiseert. Toch is in de praktijk de grens soms moeilijk te trekken; een zelfstandige krijgt meestal ook aanwijzingen over de uitvoering van de aangenomen opdracht. Bij het element arbeid wijst de mogelijkheid om zich te laten vervangen richting zelfstandige arbeid, maar dit hangt mede af van het daadwerkelijk gebruik van deze optie. De woorden 'gedurende een zekere tijd' zijn een frase gebleken. Nu de wetsbepaling geen minimum aangeeft voor de tijdsduur van een arbeidsovereenkomst, is in beginsel een arbeidsovereenkomst voor enkele uren of een dag mogelijk. De vaak korte duur en/of omvang van platformwerk sluit het bestaan van een arbeidsovereenkomst dus niet per definitie uit, maar om van het regeringsvoor- 
stel te kunnen profiteren is een langere periode nodig dan drie maanden. Waarschijnlijk is die drempel voor veel platformwerkers te hoog (bovendien kunnen platforms daar goed op sturen).

De meeste platformwerkers zullen dus op toetsing achteraf door de rechter aangewezen blijven. De rechter moet, conform de jurisprudentie van de Hoge Raad, de verschillende relevante aspecten in hun onderlinge samenhang beschouwen. Bij deze beoordeling is niet één enkel kenmerk van de contractuele relatie beslissend. Dit wordt ook wel aangeduid als een holistische benadering (Commissie Boot, 2016).

\section{Zijn platformwerkers werknemers?}

Met Bouwens ben ik van mening dat de manier waarop platforms als Uber, Helpling en Deliveroo te werk gaan, duidt op een arbeidsovereenkomst. Er is sprake van eenzijdig opgestelde gebruiksvoorwaarden en er is nauwelijks enige onderhandelingsvrijheid over de tarieven en de manier waarop arbeid wordt uitgevoerd. Ook regelen deze platforms de betalingen en hanteren ze reputatiesystemen (ratings) waarbij tijdelijke of permanente uitsluiting van het platform als sanctie kan worden opgelegd. Bij Werkspot is dit juist niet het geval. Dit platform brengt enkel vraag en aanbod bij elkaar en laat het aan de gebruikers of de transactie plaatsvindt en, zo ja, tegen welke prijs en voorwaarden. In dat geval treedt het platform slechts op als intermediair (Bouwens, 2017; Houwerzijl, 2017b). Afhankelijk van de manier waarop het platform vraag en aanbod heeft georganiseerd, maar ook afhankelijk van de specifieke situatie van elke werkende (parttimer of fulltimer, aangesloten bij meerdere platforms/opdrachtgevers of niet), kan de beoordeling dus anders uitpakken. Probleem is echter, vanuit zowel het oogpunt van efficiëntie voor (platform)bedrijven, maar ook vanuit het oogpunt van handhaving/waarborgen van publieke belangen zoals de bescherming van de platformwerkenden, dat de hierboven beschreven holistische toets casuïstisch en achteraf plaatsvindt. De rechtsonzekerheid die deze toetsingswijze creëert, bemoeilijkt de inzet van de arbeidsovereenkomst als effectief beleids- en handhavingsinstrument (Van Slooten, 2017).

Inmiddels is Uber over de kwalificatie van zijn chauffeurs in rechtszaken betrokken geraakt, onder meer in de Verenigde Staten, Frankrijk en Groot-Brittannië. Net als in Nederland is in deze landen niet de tekst van de overeenkomst (of de algemene voorwaarden) doorslaggevend. Tot nu toe is in binaire stelsels nog geen sprake van het kwalificeren van platformwerkers als werknemers, zo blijkt uit Franse en Amerikaanse rechtspraak. Anders is dit in het Verenigd Koninkrijk, waar naast de categorie employee (werknemer), die volledige bescherming onder het arbeidsrecht geniet, een derde categorie bestaat, bedoeld voor de economisch afhankelijke persoon die in juridische zin niet als ondergeschikt aan te merken valt. Het Britse recht spreekt dan over de worker. De term 'zelfstandige' wordt bewaard voor de werkelijk economisch en juridisch onafhankelijke opdrachtnemer. De hoge mate van controle door Uber op onder meer het te leveren resultaat, de prijszetting en de manier van werken speelde een doorslaggevende rol bij het 
kwalificeren van de chauffeurs als worker en Uber als werkgever in de Londense uitspraak van het Employment Tribunal (onlangs in hoger beroep bevestigd) (Central London Employment Tribunal, 2016; Employment Appeal Tribunal, 2017). Ook zelfstandig tewerkgestelde fietskoeriers zijn door deze rechtsprekende instantie gekwalificeerd als workers (Central London Employment Tribunal, 2017), maar een Britse vakbond die probeerde collectieve onderhandelingen af te dwingen met Deliveroo ving bot wegens de contractuele afspraak dat de fietskoeriers zich mogen laten vervangen en dus niet verplicht zijn de arbeid (altijd) persoonlijk te verrichten (Central Arbitration Committee Trade Union and Labour Relations, 2017). Ook in een stelsel met een tussencategorie tussen werknemer en zelfstandige blijft de casuïstische beoordeling achteraf dus voor rechtsonzekerheid zorgen.

\section{Bestendige (bij)verdiensten?}

Een ander lastig punt is de heterogeniteit van platformwerk. In de Londense Uber-zaak ging het om (bijna) fulltime werkenden. Zij waren van Uber afhankelijk voor hun bestaanszekerheid. Zij werkten ook al langere tijd voor Uber en zouden dus kunnen vallen binnen de door de Nederlandse regering aangemerkte verplicht als werknemer te bestempelen categorie. Platformwerk leent zich echter bij uitstek voor bijverdienen. De platformwebsites wijzen daar ook nadrukkelijk op. Een student kan Deliveroo-bezorger zijn en een gepensioneerde een Werkspotklusser. Is er een ondergrens aan de omvang van de overeenkomst om als werknemer aangemerkt te kunnen worden? Deze vraag wint aan urgentie, omdat de klusseneconomie actief wordt gepromoot als alternatief voor 'traditionele werkgelegenheid' (Houwerzijl, 2017b). Ook het aantal taak- of baancombineerders neemt toe (SER, 2018).

We zagen al dat artikel 7:610 BW het bestaan van een arbeidsovereenkomst niet per definitie uitsluit bij een korte duur en/of omvang van platformwerk. En volgens vaste rechtspraak van het Hof van Justitie van de Europese Unie (HvJ EU) is van belang dat sprake is van 'een reële en daadwerkelijke activiteit met economische waarde die niet van zo geringe omvang is dat het om louter marginale en bijkomstige werkzaamheden gaat'. Alhoewel in lidstaten gebruik wordt gemaakt van verschillende drempels (op basis van uren of loon), mogen volgens de jurisprudentie van het HvJ EU 'een korte duur, beperkte werktijden, onregelmatige werkzaamheden of lage productiviteit er niet automatisch toe leiden dat een arbeidsverhouding wordt uitgesloten' $(\operatorname{COM}(2016) 356,14)$. Als personen diensten aanbieden op een meer dan incidentele basis, zal daadwerkelijke bepaling van hun status als werknemer moeten plaatsvinden.

In het voorstel voor een nieuwe EU-richtlijn voor 'meer transparante en voorspelbare arbeidsvoorwaarden in de hele EU' lijkt puur bijkomstige arbeid begrensd te worden op dienstverbanden tot acht uur per maand (COM/2017). Voor alle andere werknemers beoogt de richtlijn met de invoering van bepaalde minimumnormen te bevorderen dat zij duidelijkere en beter voorspelbare arbeidsvoorwaarden krijgen. Europeesrechtelijk gaat het om een bredere categorie dan de Neder- 
landse definitie van werknemerschap. Iedereen die geen echte zelfstandige is, moet op de eerste werkdag te horen krijgen hoe lang de proefperiode duurt, hoe hij is verzekerd, wanneer hij (minimaal) kan worden opgeroepen en wat hij zal gaan verdienen. Deze regels zouden ook moeten gelden voor atypische contracten, zoals de meeste 'nieuwe' vormen van werk: 'Ook Deliveroo-koeriers of Ubermedewerkers vallen er straks onder', aldus Eurocommissaris Thyssen.

Dit voorstel is een stap in de goede richting, zeker voor de platformwerkers die buiten het bereik van het regeringsvoorstel vallen, omdat zij (nog) niet langer dan drie maanden voor een platform werkzaam zijn. Via het Europese recht zou deze (potentieel) grote groep in ieder geval iets meer rechtszekerheid en handvatten voor het claimen van een arbeidsverhouding toegespeeld krijgen. Bij niet-naleving gelden namelijk gunstige aannames in verhouding tot de ontbrekende informatie, zoals een vermoeden van een arbeidsrelatie voor onbepaalde tijd als geen informatie is verstrekt over de duur van de arbeidsrelatie, het vermoeden van een voltijdse betrekking als geen informatie is verstrekt over de gewaarborgde betaalde uren, en een vermoeden van afwezigheid van een proeftijd als geen informatie is verstrekt over het bestaan en de duur van een proeftijd. Ook komt de werknemer al snel in aanmerking voor omkering van bewijslast.

\section{Het platform als intermediair of werkgever?}

Het Europese voorstel zal ook betekenen dat platforms transparanter moeten worden over hun positie. Daarbij helpt mee dat het HvJ EU de instrumentele beeldvorming dat platforms slechts een faciliterend en neutraal 'digitaal prikbord' zouden zijn, heeft doorgeprikt voor Uber (Hof van Justitie EU, 2017). Terwijl Uber zich positioneerde als een 'technologiebedrijf dat passagiers verbindt met chauffeurs', waardoor het onder de EU-richtlijn inzake e-commerce zou vallen en niet aan sectorale toetredingsvoorwaarden gebonden zou zijn, oordeelde het $\mathrm{HvJ}$ EU dat Uber wel degelijk als taxibedrijf moest worden aangemerkt, waardoor regulering met betrekking tot de taxisector of het personenvervoer integraal van toepassing is. Dat dezelfde redenering kan worden toegepast op bijvoorbeeld Helpling, dat dan als schoonmaakbedrijf zou kwalificeren, is denkbaar.

Complicerend is dat het bij platformwerk om een driehoeksverhouding gaat, net zoals bij (traditionele) uitzendarbeid. Er zijn altijd ten minste drie partijen betrokken: de klant, de werker en het platform. Als de werkende als werknemer kwalificeert, ten opzichte van wie dan? De klant of het platform? Helpling gaat uit van de eerstgenoemde situatie; volgens de door de gebruikers (schoonmakers en de afnemers van schoonmaakwerk) van het platform te accepteren algemene voorwaarden is er geen sprake van werknemerschap met Helpling, maar met de klant. Bepaald wordt dat rechtstreeks een overeenkomst tussen beide wordt gesloten, waarin Helpling geen partij is (Verhulp, 2018). Gelet op de toepasselijke Regeling Dienstverlening aan Huis is de schoonmaker daarom zelf verantwoordelijk voor de correcte afdracht van belastingen en premies en het aangaan van een arbeidsongeschiktheidsverzekering (zie over Helplings model ook Frenken e.a., 2017, 50-51). 
Het organisatie- en verdienmodel van Helpling en andere platforms kan echter alsnog in de knel komen door toepasselijkheid van de Wet allocatie arbeidskrachten door intermediairs (Waadi). De Waadi ziet zowel toe op arbeidsbemiddeling als op terbeschikkingstelling van arbeidskrachten. De laatste activiteit omvat mede de terbeschikkingstelling van anderen dan werknemers, en mogelijk moet ook bij arbeidsbemiddeling een bredere categorie worden aangehouden. Verhulp heeft de proef op de som genomen voor drie platforms, waaronder Helpling, en concludeert dat ze alle drie in strijd met de Waadi lijken te handelen. Waarschijnlijk geldt dit voor veel meer platforms, aangezien platformwerkers een deel van hun loon/vergoeding betalen aan het platform, hetgeen de Waadi juist verbiedt. Anders dan artikel 7:610 BW, waarop door werkenden zelf een beroep moet worden gedaan, wordt de Waadi publiekrechtelijk gehandhaafd. Dit is dus een mooie kans voor de overheid om, via de Inspectie SZW, de positie van platformwerkers $\mathrm{nu}$ al - op basis van het geldende recht - te versterken (Verhulp, 2018).

\section{Hoe verder?}

In binnen- en buitenland neemt de bezorgdheid toe over de arbeidsomstandigheden en -voorwaarden van platformwerkers die zijn aangesteld als (schijn)zelfstandige. Bij het verkennen van beleidsmogelijkheden om de positie en de bescherming van deze groeiende groep werkenden te versterken, komen vele juridische vragen naar boven. Een cruciaal aspect betreft de kwalificatie van de platformwerkers. Als werkenden in de gig-economie kwalificeren als werknemer, is het risico van precarisering minder groot dan bij een kwalificatie als zelfstandige. De rechtsonzekerheid die de holistische toetsingswijze creëert, bemoeilijkt echter de inzet van de arbeidsovereenkomst als beleidsinstrument. Aan een dwingendrechtelijke kwalificatie als arbeidsovereenkomst bij een (te) laag tarief, zoals voorgesteld in het regeerakkoord, kleeft dit manco niet. Mede gelet op de preventieve werking die er van uitgaat, kan dit instrument de scherpe kantjes van de kwalificatievraag afschaven voor (langer dan drie maanden werkende) platformwerkers en andere aan de onderkant van de arbeidsmarkt opererende schijnzelfstandigen. Voor de waarschijnlijk aanzienlijke groep platformwerkers die drie maanden werken voor een platform niet haalt, moeten we daarentegen naar de Europese wetgever kijken. Het hierboven besproken richtlijnvoorstel van de Europese Commissie is een stap in de goede richting, omdat dit op procedurele wijze de duimschroeven voor platforms en andere verkapte werkgevers of intermediairs aandraait. Moeten we nu meteen oppassen dat de innovatiekracht van de platforms daarmee in de knel komt? Ik denk dat dat meevalt. De beoogde maatregelen laten nog heel veel ruimte voor platformondernemerschap. Bij het reguleren van nieuwe vormen van arbeid in het verleden (zoals uitzendarbeid), is steeds gebleken dat dit leidt tot een 'vlucht naar voren'. Platforms zullen eerder geneigd zijn tot constructief overleg met vakbonden of andere belangenbehartigers van de platformwerkers over bijvoorbeeld sectoraal maatwerk als zij de hete adem van de wetgever in de nek voelen. Hoog tijd dus om deze oude succesformule van 'bargaining in the shadow of the law' weer eens uit de krochten van ons poldermodel op te diepen. 


\section{Literatuur}

Bouwens, W.H.A.C.M. (2017). Position paper t.b.v. rondetafelgesprek Werk in de platformeconomie op 16 november 2017. www.tweedekamer.nl, geraadpleegd op 27 maart 2018.

Central Arbitration Committee Trade Union and Labour Relations 14 november 2017 (Independent Workers' Union of Great Britain (IWGB)/Deliveroo).

Central London Employment Tribunal 2 august 2017 (Gascoigne/Addison Lee Ltd); 23 maart 2017 (Boxer/Excel Group Services Ltd.); 5 januari 2017 (Dewhurst/Citysprint UK Ltd.).

Commissie Boot (2016). Commissie (model)overeenkomsten in het kader van de wet DBA.

Dijck, J. van, Poell, T., \& Waal, M. de (2016). De platformsamenleving: Strijd om publieke waarden in een online wereld. Den Haag: WRR.

Deliveroo (2017). Position paper t.b.v. rondetafelgesprek Werk in de platformeconomie op 16 november 2017. www.tweedekamer.nl, geraadpleegd op 27 maart 2018.

Employment Appeal Tribunal 10 november 2017 (Uber B.V. and others/Aslam and others).

Employment tribunals 28 oktober 2016 (Aslam and others/Uber B.V. and others).

Foodora (2017). Position paper t.b.v. rondetafelgesprek Werk in de platformeconomie op 16 november 2017. www.tweedekamer.nl, geraadpleegd op 27 maart 2018.

Frenken, K., Waes, A. van, Smink, M., \& Est, R. van (2017). Eerlijk delen - Waarborgen van publieke belangen in de deeleconomie en de kluseconomie. Den Haag: Rathenau Instituut.

Europese Commissie (2016). Een Europese agenda voor de deeleconomie. Brussel: $\operatorname{COM}(2016) 356: 14$.

Europese Commissie (2017). Voorstel voor een richtlijn voor meer transparante en voorspelbare arbeidsvoorwaarden Brussel: COM(2017)797 final.

Hof van Justitie EU 20 december 2017, ECLI:EU:C:2017:981 (C-434/15).

Houwerzijl, M.S. (2017a). Arbeid en arbeidsrecht in de digitale platformsamenleving: transnationale dimensies en dilemma's. TRA, 2017/59.

Houwerzijl, M.S. (2017b). Arbeid en arbeidsrecht in de digitale platformsamenleving: een verkenning. TRA, 2017/14.

Kool, L., \& Est, R. van (2017). Opwaarderen: Borgen van publieke waarden in de digitale samenleving. Den Haag: Rathenau Instituut.

Milbourn, T. (2015). In the future, employees won't exist. Techcrunch. https://techcrunch. com/2015/06/13/in-the-future-employees-wont-exist/, geraadpleegd op 20 maart 2018.

Prassl, J., \& Risak, M. (2017). The legal protection of crowdworkers: four avenues for workers' rights in the virtual realm. In: P. Meil \& V. Kirov (red.), Policy Implications of Virtual Work. Cham: Springer, 273-295.

Regeerakkoord 2017-2021 (2018). Vertrouwen in de toekomst. www.rijksoverheid.nl, geraadpleegd op 20 maart 2018.

SER (2018). De vele kanten van banen combineren. Den Haag: SER.

Slooten, J.M. van (2017). Position paper t.b.v. rondetafelgesprek Werk in de platformeconomie op 16 november 2017. www.tweedekamer.nl, geraadpleegd op 27 maart 2018.

Verhulp, E. (2018). Platformwerkers verdienen meer! ArbeidsRecht 2018, 1. 